\title{
PENGARUH KECELAKAAN KERJA TERHADAP PRODUKTIVITAS KERJA KARYAWAN PT. MARUKI INTERNATIONAL INDONESIA
}

\author{
Suradi \\ Dosen Program Studi Teknik Industri Fakultas Teknik Universitas Islam Makassar \\ Jl. Perintis Kemerdekaan No, 29 Makassar \\ Email : suradi.najamuddin@yahoo.com
}

\begin{abstract}
ABSTRAK
Penyebab kecelakaan kerja ada empat faktor diantaranya: Faktor nasib dari par karyawan, faktor lingkungan fisik pada karyawan, seperti mesin, gedung,ruangan, peralatan, faktor kelalaian manusia dan faktor ketidak serasian kobinasi faktor-faktor produksi yang di kelolah dalam perusahaan. Metode penelitian yan digunakan adalah observasi yaitu pengambilan data dengan meninjau dan meneliti secara langsung hal-hal yang berkaitan dengan objek penelitian. Interview yaitu dengan mengadakan wawancara secara langsung dengan kepala seksi, karyawan maupun pihak-pihak yang berhubungan dengan keselamatan dan kesehatan kerja.Hasil penelitian dari nilai tabel $\mathrm{F}$ pada $\alpha 5 \%$; di mana $\mathrm{db}_{\text {reg }}=2$ dan $\mathrm{db}_{\text {res }}=\mathrm{n}-3=9$ adalah 2,262 (Interpolasi). Dengan demikian nilai hitung $\mathrm{F}>$ nilai tabel $\mathrm{F}$, maka $\mathrm{H}_{0}$ di tolak, artinya koefisien regresi signifikan Bahwa lingkungan kerja menpunyai hubungan sangat erat dan mempunyai pengaruh yang signifikasi antara pengaruh kecelakaan akibat alat pelindung diri dan akibat kelalaian manusia terhadap lingkungan kerja.
\end{abstract}

\section{Kata Kunci: Kecelakaan kerja, produktivitas}

\section{PENDAHULUAN}

\subsection{Latar Belakang}

Perusahaan perlu memelihara keselamatan para karyawan, ataupun buruh, ini menyangkut keselamatan fisik ataupun mental. Penurunan kesehatan para karyawan akan mengakibatkan kecenderungan tingkat ketidak hadiran yang tinggi sehingga mengakibatkan produksi yang menurung dan perusahaan mengalami kerugian. keselamatan kerja merupakan kesealamatan yang bertalian dengan mesin, pesawat, alat kerja, bahan dan proses pengelolahanya landasan tempat kerja dan lingkungannya serta cara-cara melakukan pekerjaan. Keselamatan kerja merupakan sarana untuk pencegahan kecelakaan, cacat, dn kematian sebagai akibat kecelakaan kerja.

Penyebab kecelakaan kerja ada empat faktor diantaranya: Faktor nasib dari par karyawan, faktor lingkungan fisik pada karyawan, seperti mesin, gedung,ruangan, peralatan, faktor kelalaian manusia dan faktor ketidak serasian kobinasi faktor-faktor produksi yang di kelolah dalam perusahaan.

PT. Maruki international indonesia adalah suatu usaha yang bergerak di bidang butsudan, menggap pengting variabel program kelamatan dan kesehatan kerja, haltersebut dibuktikan dengan adanya penggunaan alat-alat perlindungan diri seperti sarung tangan, sepatu, hadset dan masker di tempat kerja, serta pengaturan udara yang cukup dan adapula petunjuk dan peringatan di tempat kerja.

PT. Maruki International Indonesia dalam proses produksinya menggunakan bahan yang kompleks serta peralatan dengan tingkat teknologi yang semakin tinggi. Proses produksi yang menggunakan teknologi tinggi akan berlangsung dengan cepat serta evesien sehinnga menghasilkan produk yang bermutu 
dengan harga yang bersain, tetapi disisi lain penggunaan teknologi tinggi dapat menimbulkan kemungkinan bahaya yang lebih besar yaitu adanya kecelakaan kerja, dan penyakit akibat kerja. Oleh karenanya PT. Maruki International Indonesia menganggap perlindungan terhadap tenaga kerja sangat di perlukan agar perusahaan tida kehilangan tenaga kerja yang berakibat menghmbat proses produksi yang akan merugikan perusahaan akibat kecelakaan yang terjadi di tempat kerja tersebut.

Perushaan yang menggap perlindungan kerja itu penting tentunya akan memperhatikan hal-hal tersebut untuk menghindri menurungnya produksi dari perusahaan, sebab dengan adanya kecelakaan kerja tersebut dapat pula mengkibatkan menurungnya produktivitas karyawan.

\subsection{Rumusan masalah}

Berdasarkan uraiaan diatas, dapat diajukan rumusan masalahnya yaitu :

a. Apakah ada pengaruh antara kecelakaan kerja terhadap produktivitas kerja karyawan di PT. Maruki International Indonesia?

b. Bagaimana hubungan peningkatan produktivitas kerja karyawan terhadap keselamatan kerja .

\subsection{Tujuan penelitian}

Sesuai dengan judul dan permaslahan yang telah dirumuskan dalam penelitian maka tujuan dari penelitian ini adalah :

a. Untuk mengetahui apakah ada pengaruh antara keselamatan kerja terhadap produktivitas kerja karyawan di PT. Maruki International Indonesia.

b. Untuk mengetahui bagaimana hubungan peningkatan produktivitas karyawan terhadap keselamatan kerja.

\section{METODOLOGI PENELITIAN}

\subsection{Tempat Dan Waktu Penelitian}

a. Tempat penelitian dilaksanakan di PT. Maruki International indonesia, yang terletak di Jl. Kapasa Raya Makassar, Propinsi Sulawesi Selatan. b. Waktu penelitian dilaksanakan pada tanggal 1 maret samapai dengan tanggal 30 april 2012.

\subsection{Metode Pengumpulan Data}

a. Observasi yaitu pengambilan data dengan meninjau dan meneliti secara langsung hal-hal yang berkaitan dengan objek penelitian.

b. Interview yaitu dengan mengadakan wawancara secara langsung dengan kepala seksi, karyawan maupun pihakpihak yang berhubungan dengan keselamatan dan kesehatan kerja.

c. Penelitian ke perpustakaan (library research) yaitu pengumpulan data dengan mencari literatur dan membaca buku-buku yang berkaitan dengan judul yang akan diangkat.

\section{ANALISA DAN PEMBAHASAN}

Hasil penelitian yang dilakukan di PT. Maruki International Indonesia. Populasinya adalah jumlah dari keseluruhan objek (satuan -satuan individu) atau karyawan yang mempunyai tingkat kecelakaan kerja yang di peroleh langsung dari poliklinik PT. Maruki International Indonesia dan hasil produktivitas kerja yang di peroleh dari kepala bagian produksi.

Jumlah seluruh karyawan PT. Maruki International Indonesia adalah 600 orang yang terdiri dari 100 orang di bagian kantor atau manajemen, sedangkan di bagian produksi 500 orang. Penelitian dari pengelolah data adalah Uji Variabel Independent adalah Keselamatan dan Kesehatan Kerja pada karyawan sedangkan Variabel Dependent adalah produktivitas kerja karyawan.

Faktor yang berhubungan dengan produktivitas kerja adalah keselamatan kerja,karena merupakan faktor intern yang mempunyai pengaruh yang besar terhadap pelaksanaan tugas karyawan.

Untuk mengetahui yang mengandung makna bahwa dalam persamaan regresi terdapat satu variabel Dependent dan lebih dari satu Variabel Independent. 
Tabel 3.1. Data Kecelakaan Kerja Akibat Alat Pelindung Diri Pada PT.Maruki International pada Tahun 2010

\begin{tabular}{|c|c|c|c|c|c|}
\hline \multirow[t]{2}{*}{$\begin{array}{c}\text { Bulan } \\
\text { kejadian } \\
\text { kecalakaan } \\
\text { kerja }\end{array}$} & \multicolumn{2}{|c|}{$\begin{array}{c}\text { Jenis } \\
\text { kecelakaan } \\
\text { kerja akibat } \\
\text { alat } \\
\text { pelindung } \\
\text { diri }\end{array}$} & \multirow[t]{2}{*}{$\mathrm{Jmh}$} & $\begin{array}{c}\text { Jenis } \\
\text { kecelakaan } \\
\text { kerja akibat } \\
\text { kelalaiaan } \\
\text { manusia }\end{array}$ & $\mathrm{Jmh}$ \\
\hline & $\mathrm{R}$ & $\mathrm{S}$ & & $\mathrm{R}$ & \\
\hline
\end{tabular}

\begin{tabular}{lllllllll}
\hline Januari & - & - & - & - & - & - & - & - \\
\hline
\end{tabular}

\begin{tabular}{lllllllll}
\hline Februari & - & 1 & 2 & 3 & - & - & - & - \\
\hline Maret & - & - & 1 & 1 & - & - & - & -
\end{tabular}

\begin{tabular}{lllllllll} 
April & - & - & 1 & 1 & - & - & - & - \\
\hline Mei & 1 & 4 & 2 & 7 & - & - & - & -
\end{tabular}

\begin{tabular}{lllllllll}
\hline Juni & - & 5 & 1 & 6 & - & - & - & - \\
\hline Juli & - & 1 & - & 1 & - & 1 & - & 1 \\
\hline
\end{tabular}

\begin{tabular}{lcccccccc}
\hline Agustus & - & - & - & - & - & 2 & - & 2 \\
\hline September & - & - & - & - & - & 2 & - & 2 \\
\hline Oktober & - & 1 & - & 1 & - & 1 & - & 1 \\
\hline November & - & 3 & - & 3 & - & 1 & - & 1 \\
\hline Desember & - & 4 & - & 4 & - & - & - & - \\
\hline \multicolumn{1}{c}{ Total } & 1 & 19 & 7 & 31 & & 7 & - & 7 \\
\hline
\end{tabular}

Jadi data dari tabel 1. Di peroleh bahwa hasil tenaga kerja karyawan PT. Maruki international indonesia pada tahun 2010 terlihat bahwa kejadian paling tinggi pada bulan mei 2010 yaitu terdapat 7 kejadian kecelakaan kerja dari total 27 kejadian kecelakaan kerja padapriode 2010dan pada data kejadian kecelakaan kerja akibat manusia pada PT. Maruki International Indonesia pada tahun 2010 yang paling tinggi terlihat pada bulan agustus dan september yang masing-masing ada 2 orang.
Tabel 3.2. Data Produktivitas Kerja Di PT.Maruki International Indonesia pada Tahun 2010

\begin{tabular}{clcc}
\hline No & \multicolumn{1}{c}{ Bulan } \\
produksi & $\begin{array}{c}\text { Jumlah } \\
\text { pengiriman } \\
\text { barang } \\
\text { dalam } \\
\text { bulan }\end{array}$ & $\begin{array}{c}\text { Jumlah } \\
\text { kapasitas } \\
\text { produksi }\end{array}$ \\
\hline 1 & Januari & 4 & 520 unit \\
\hline 2 & Februari & 7 & 910 unit \\
\hline 3 & Maret & 5 & 650 unit \\
\hline 4 & April & 5 & 650 unit \\
\hline 5 & Mei & 5 & 650 unit \\
\hline 6 & Juni & 6 & 780 unit \\
\hline 7 & Juli & 8 & 1040 unit \\
\hline 8 & Agustus & 6 & 780 unit \\
\hline 9 & September & 5 & 650 unit \\
\hline 10 & Oktober & 6 & 780 unit \\
\hline 11 & November & 6 & 780 unit \\
\hline 12 & Desember & 5 & 650 unit \\
\hline & Jumlah & 68 & 8840 unit \\
\hline
\end{tabular}

Sumber : Data Primer

Jadi dari tabel 2. Di peroleh bahwa jumlah hasil produksi berada pada bulan juli 2010 pada PT.Maruki International Indonesia dengan jumlah kapasitas produksi 1040 unit dengan 8 kali pengiriman sedangkan jumlah kapasitas terendah berada pada bulan januari dengan kapasitas produksi 520 unit dengan 4 kali pengiriman.

Sedangkan jumlah kapasitas produksi keseluruhan pada tahun 2010 adalah 8840 unit dengan 68 pengiriman.

Berdasarkan hasil pengelolahan data, di peroleh nilai uji signifikansi regresi ganda. Oleh karena itu, dapat di katakan bahwa lingkungan kerja mempunyai hubungan sangat erat yang mempunyai pengaruh yang signifikasi antara pengaruh kecelakaan kerja akibat alat pelindung diri dan akibat kelalaian manusia terhadap lingkungan kerja serta produktivitas kerja karyawan pada PT. Maruki International Indonesia. 


\section{PENUTUP}

\subsection{Kesimpulan}

Berdasarkan hasil penelitian yang dilakukan pada PT. Maruki International Indonesia maka peneliti dapat mengambil kesimpulan bahwa :

1. Nilai tabel $\mathrm{F}$ pada $\alpha 5 \%$; di mana $\mathrm{db}_{\text {reg }}=$ 2 dan $\mathrm{db}_{\text {res }}=\mathrm{n}-3=9$ adalah 2,262 (Interpolasi). Dengan demikian nilai hitung $\mathrm{F}>$ nilai tabel $\mathrm{F}$, maka $\mathrm{H}_{0}$ di tolak, artinya koefisien regresi signifikan (berarti).

2. Dapat di katakan bahwa lingkungan kerja menpunyai hubungan sangat erat dan mempunyai pengaruh yang signifikasi antara pengaruh kecelakaan akibat alat pelindung diri dan akibat kelalaian manusia terhadap lingkungan kerja.

\subsection{Saran}

Berdasarkan kesimpulan di atas maka peneliti memberikan saran - saran sebagai berikut:

1. Untuk menghindari kecelakaan kerja yang terjadi pada PT. Maruki International Indonesia perusahaan harus menerapkan Program Sistem Keselamatan dan Kesehatan kerja. Hal ini di karenakan berdasarkan penelitian yang telah dilakukan, kedua program tersebut sangat berpengaruh terhadap pengurangan kecelakaan kerja yang terjadi pada PT.Maruki International Indonesia.

2. Pihak Pemerintah Daerah agar lebih serius dan memperketat pengawasan dan pemberian sanksi pada perusahaan yang melanggar aturan K3 dan tujuan K3 yang sebenarnya.

3. Sebaiknya penerapan K3 lebih di fokuskan pada masalah penyediaan lingkungan kerja yang aman,sehat, nyaman, dan efisien.

4. Lebih memperhatikan penggunaan Alat Pelindung Diri ( APD ) bagi karyawan yang melakukan aktifitas produksi pada jam - jam kerja.

5. Untuk bagian pelaksanaan dan pengawasan SMK3 agar lebih atau sering melakukan sosialisasi tentang K3 di tempat kerja atau pemberian training khusus bagi karyawan yang memiliki tingkat pendidikan atau pengetahuan rendah mengenai Keselamatn dan Kesehatan Kerja.

\section{DAFTAR PUSTAKA}

Hasan Ikbal, Analisis Data Penelitian Dengan Statistik. 2004. Jakarta: Bumi Aksara.

http:/www.Google.com.Produktivitas, Rabu 17 Mei 2012

http:/www.Google.com.Kecelakaan Kerja, Rabu 17 Mei 2012

Mulyono Maulend. 1993. Produktivitas Kerja. Jakarta : Gramedia

Ramli Soehatman, Sistem Manajemen Keselamatan \& Kesehatan Kerja. 2004. Jakarta : Dian Rakyat

Santoso Gempur, Dr. 2004. Management Losses Dalam Manajemen Keselamatan Dan Kesehatan Kerja.surabaya :Prestasi pustaka

Somabtri Ating,Drs dan Muhidin Ali Sambas, S.Pd.2006.Aplikasi Statistika Dalam Penelitian.Bandung:Pustaka Setia Bandung

Sondang P.Siagian,Prof.Dr.Sistem Informasi Manajemen.1999.Jakarta: Bumi Aksara

Suardi Rudi,Sistem manajemen Keselamatan \& Kesehatan Kerja.2007. Jakarta:PPM

Sudjana (1989),Metode Statistika,Penerbit Tarsito,Bandung

Sulaksomono,M.1997. Kecelakaan Kerja.Jakarta:Gramedia

Suma'mur dan Santoso Gempur, Dr. 2004. Manajemen Keselamatan dan Kesehatan Kerja.Surabaya:Prestasi Pustaka 